\title{
Functional importance of the internal anal sphincter in fistula surgery
}

\author{
Correspondence for the original article entitled "For many high anal fistulas, lay open is \\ still a good option" by GK Atkin, J Martins, P Tozer, P Ranchod, RKS Phillips (2011) \\ Tech Coloproctol 15:143-150
}

\author{
Andrew P. Zbar \\ Received: 11 May 2011/ Accepted: 8 September 2011/Published online: 5 October 2011 \\ (C) Springer-Verlag 2011
}

Sir,

I congratulate Atkin and colleagues for their recent retrospective review of anal fistulotomy in high fistulas [1]. It proves the inestimable value of standardized surgery and regulated axial and coronal operative records using images as part of reporting. Their work provides convincing evidence that judicious external anal sphincter (EAS) division has a limited impact on continence but to prove their point that division of the healthy internal anal sphincter (IAS) below the fistula site is harmful, we need randomized longer-term outcome trials of IAS-preserving techniques like the ligation of the intersphincteric fistula tract (LIFT) procedure. We know that rectoanal inhibition (an IAS function) is differentially affected with a more rapid wave of recovery following balloon distension in incontinent patients with known EAS atrophy or defects when compared with healthy volunteers [2]. This is one defense mechanism against incontinence.

Further, we know that there is a constitutive sphincter disposition, (a distal deficiency; EAS with poor IAS/EAS overlap), in some patients about to undergo deliberate IAS division for chronic anal fissure, that probably leaves the anal canal relatively unsupported and leads to predictable fecal leakage [3]. There are also significant differences in measurable parameters, (such as the area under the inhibitory curve), of the rectoanal inhibitory reflex detectable in the mid- and distal sphincter in incontinent patients when compared with continent cohorts following IAS division [4]. The data regarding deliberate IAS preservation (and repair) in high fistulas are currently too small to permit us to draw meaningful conclusions as to its significance. There were no differences

\footnotetext{
A. P. Zbar $(\bowtie)$

Department of Surgery and Transplantation,

Chaim Sheba Medical Center, Tel Aviv, Israel

e-mail: apzbar1355@yahoo.com
}

between preserved and non-preserved groups in reported incontinence in a randomized controlled trial [5] although the resting pressures of the IAS-preserved group were higher than those of patients in whom it was not protected [6]. I would suggest, as Atkin and colleagues do, that IAS preservation where possible in most fistula management should be strongly recommended based on these physiological and functional observations. It may well be that we also could benefit from reclassifying our high fistulas to better direct preoperative imaging and to reflect clinical situations where the objective of IAS preservation can be achieved.

Conflict of interest The author declares that there is no conflict of interest.

\section{References}

1. Atkin GK, Martins J, Tozer P, Ranchod P, Phillips RKS (2011) For many high anal fistulas, lay open is still as good option. Tech Coloproctol 15:143-150

2. Zbar AP, Aslam M, Gold DM, Gatzen C, Gosling A, Kmiot WA (1998) Parameters of the rectoanal inhibitory reflex in patients with idiopathic fecal incontinence and chronic constipation. Dis Colon Rectum 41:200-208

3. Zbar AP, Kmiot WA, Aslam M et al (1999) Use of vector volume manometry and endoanal magnetic resonance imaging in the adult female for assessment of anal sphincter dysfunction. Dis Colon Rectum 42:1411-1418

4. Zbar AP, Aslam M, Allgar V (2000) Faecal incontinence after internal sphincterotomy for anal fissure. Tech Coloproctol 4:25-28

5. Zbar AP, Ramesh J, Beer-Gabel M, Salazar R, Pescatori M (2003) Conventional cutting vs. internal anal sphincter-preserving seton for high trans-sphincteric fistula: a prospective randomized manometric and clinical trial. Tech Coloproctol 7:89-94

6. Zbar A, Pescatori M (2005) Internal anal sphincter preservation with seton rerouting in high transsphincteric anal fistula. Dis Colon Rectum 48:1666-1667 